\title{
THE HANDHELD MOBILE LASER SCANNERS AS A TOOL FOR ACCURATE POSITIONING UNDER FOREST CANOPY
}

\author{
J. Chudá ${ }^{1}$, M. Hunčaga ${ }^{1}$, J. Tuček $^{1}$ and M. Mokroš ${ }^{2,3}$

\begin{abstract}
${ }^{1}$ Department of Forest Resource Planning and Informatics, Faculty of Forestry, Technical University in Zvolen, 96053 Zvolen, Slovakia-xchudaj@tuzvo.sk, xhuncaga@tuzvo.sk, tucek@tuzvo.sk;

${ }^{3}$ Department of Forest Harvesting, Logistics and Ameliorations, Faculty of Forestry, Technical University in Zvolen, Zvolen, Slovakia - martin.mokros@tuzvo.sk
\end{abstract} \\ ${ }^{2}$ Faculty of Forestry and Wood Sciences, Czech University of Life Sciences Prague, Prague, Czech Republic - mokros@ fld.czu.cz
}

\section{Commission I, WG I/7}

KEY WORDS: Handheld Mobile Laser Scanner, Simultaneous Localization and Mapping, SLAM, Forest

\begin{abstract}
:
Nowadays it is important to shift positional accuracy of object measurements under the forest canopy closer to the accuracy standards for land surveys due to the requirements in the field of ecosystem protection, sustainable forest management, property relations, and land register. Simultaneously, it is desirable to use the technology of environmental data acquisition which is not time consuming and cost demanding. Global Navigation Satellite Systems (GNSS) are the most used for positioning today. However, the usefulness and also the accuracy of the measurements with this technology depend on various factors (the strength of the GNSS signal, the geometric position of satellites, the multipath effect etc.). Based on the above mentioned facts, the usability of technology independent of GNSS indicates an ideal solution for positioning under the forest canopy. Several studies have studied the usability of Handheld Mobile Laser Scanners (HMLS) in complex environment. The goal of this paper was to verify a new data collection approach (HMLS with Simultaneous Localization and Mapping (SLAM) technology) for the forest environment practice. The main objective of our study was to reach a precision which complies with the accuracy standards for land surveys. The RMSE of derived positions from point cloud, produced by SLAM devices were $25.3 \mathrm{~cm}$ and $28.4 \mathrm{~cm}$, for ZEB REVO and ZEB HORIZON, the handheld mobile laser SLAM scanners used in this study. ZEB HORIZON achieved twice as big accuracy of diameter of breast height (DBH) estimation as ZEB REVO.
\end{abstract}

\section{INTRODUCTION}

Activities related to natural resource management, among other things, depend on precise localization. Forest is heterogenous environment and has a significant impact on the quality and strength of the GNSS signal. The influence of diverse morphological variability of vegetation cover and various terrain conditions cause the selection of satellites with unsuitable geometric position (the canopy does not provide enough space which is needed to record accurate satellite observations) (Bauwens et al., 2016). Moreover, the multipath effects caused by the reflection of the signal from barrier decrease the positional accuracy. All mentioned factors cause the problem of significant deterioration of the received signal quality and strength (Xie and Petovello, 2015) what leads to inaccurate positioning with certain devices and methods. To solve this issue and provide accurate positioning technology which is able to collect the precise data in spite of GNSS signal absence is necessary to use in the field of forestry.

SLAM technology used by handheld mobile laser scanners could serve as a more efficient method for data acquisition in challenging environment such as dense forest. Technology comprises the simultaneous estimation of a robot's position equipped with on-board sensors and the environment model construction that the sensors perceive, instead of using GNSS within the navigation module (Cadena et al., 2016). Optimal functioning of the alignment algorithm occurs in environments

\footnotetext{
* Corresponding author
}

with well-distributed static unique surface features all around the sensor, providing consistent laser returns to facilitate convergence in the processing algorithms (Bauwens et al., 2016; James and Quinton, 2014).

Traditional static mapping methods do not meet the requirements of efficiency and productivity in challenging environment (Tucek et al. 2016). One of the most promising technology able to provide efficiency and productivity within forest are those that use laser scanners as a main sensor to create the 3D model of environment with positioning. It is necessary to say that the high potential of various types of laser scanning technologies was described by several authors (Chen et al., 2019; Hyyppä et al., 2020a; James and Quinton, 2014; Liang et al., 2019; Tomaštík et al., 2017 and others). The most commonly used type within forestry research is Terrestrial Laser Scanning (TLS). TLS is able to obtain detailed tree attributes as a basis of the forest inventories and acquire sub-centimetre level of detail (Liang et al., 2016). However, other types of laser scanning technologies are capable of capturing similar point cloud data as TLS and simultaneously bring a benefit of movability and higher data collection rate. The Mobile Laser Scanning (MLS) techniques can according to Hyyppä et al. (2020b) be divided into phone-based scanning, vehicle based scanning, Unmanned Aircraft Vehicle (UAV) - based, handheld and other personal laser scanning techniques. The evaluation of the product acquired by these data collection approaches was described (Čerňava et al., 2019; Hyyppä et al., 
2017; Liang et al., 2016; Oveland et al., 2018, 2017; Tomaštík et al., 2017). The automatic estimation of tree position and stem diameter using a moving terrestrial laser scanner was described in Oveland et al. (2017). In the study 14 of the 18 trees on the $250 \mathrm{~m}^{2}$ plot were detected; the difference between the field measured and the estimated DBH varied between $-1 \mathrm{~cm}$ and 3 $\mathrm{cm}$. In Čerňava et al. (2019) MLS data were compared with a set of reference DBH measurements and they achieved a rootmean-square error (RMSE) of $3.06 \mathrm{~cm}$. Hyyppä et al. (2017) demonstrated the Kinect and Google Tango depth sensors usability for tree stem mapping in comparison with the caliper and tape measured data set. The RMSE of Kinect and Tango DBH estimations were $1.90 \mathrm{~cm}$ and $0.73 \mathrm{~cm}$ respectively. In Hyyppä et al., (2020b) pulse-based backpack laser scanner with in-house developed SLAM was used. The term stem curve was used to refer to the stem diameter. The RMSE of stem curves was below $6 \%$ in the easy plot (at all heights up to $8 \mathrm{~m}$ ), and the RMSE stays below $9 \%$ in the case of the medium plot (at all heights up to $9 \mathrm{~m}$ ). The determination of the reference tree positions was in this study based on the circle's coordinates in the TLS point cloud at the height of $1.3 \mathrm{~m}$. However, the accuracy of tree position was connected with the distance between reference trees derived from TLS point cloud and detected trees. The three ground based laser measurement methods: terrestrial laser scanner, handheld laser scanner and a backpack laser scanner (BPLS) were compared in Oveland et al. (2018). The reference data was measured by total station and GNSS technology; the DBH was measured with a caliper. They achieved RMSE of DBH $6.2 \mathrm{~cm}$ (TLS), $3.1 \mathrm{~cm}$ (HMLS) and 2.2 cm (BPLS) and positional RMSE were $82 \mathrm{~cm}$ (TLS), $20 \mathrm{~cm}$ (HMLS) and $62 \mathrm{~cm}$ (BPLS). All of the mentioned approaches connect the high data collection rate with the possibility to record large areas effectively. However, in field of forestry the HMLS with SLAM is very economic and useful technological solution for repeated data capture, processing and evaluation of stand features.

The usability of HMLS in complex environment has been studied in several studies (James and Quinton, 2014; Perugia et al., 2019; Ryding et al., 2015). In these studies authors demonstrated that HMLS mapping in complex environment (the coastal cliff site) is approximately 40 times faster than using TLS and six times as fast as using a photo-survey, processed by structure from motion and multi-view stereo algorithms (James and Quinton, 2014). Moreover, it brings a proof of ability to extract diameter at breast height (DBH) comparable with TLS estimation. The trunks with DBH $>10 \mathrm{~cm}$ were examined, and modelling success rate of $91 \%$ was achieved (Ryding et al., 2015). The influence of scan density on the estimation of single-tree attributes was demonstrated in Perugia et al. (2019) where the results provided the $10 \mathrm{~m}$ scan path, with an omission error of $6 \%$ in comparison with a single-tree reference data.

This study is aimed at the usability of handheld mobile laser scanning in forest environment with application of SLAM technology as an economic and effective alternative to common data collection approaches.

The goal of this paper is to verify a new data collection approach (HMLS with SLAM technology) for the forest environment practice, specifically, to map tree positions and to estimate DBH using point clouds from HMLS and compare the results with reference data set collected by standard methods of geodesy and forest mensuration. The main objective was to reach a precision which complies with the accuracy standards for land surveys.

\section{MATERIAL AND METHODS}

\subsection{Study area}

This study was conducted in a managed forest located in the Central Slovakia (Figure 1). The forest stand is managed by the Forest Enterprise of the Technical University in Zvolen. The dominant tree species in the study area is 115 years old oak (Quercus petraea (Matt.) Liebl.) (93\%) followed by pine (Pinus sylvestris L.) (7\%) and European hornbeam (Carpinus betulus L.) in the understory. The plot is a circular area with a radius of $16 \mathrm{~m}$, the centre of the plot is on $48^{\circ} 36^{\prime} 17.24462 " \mathrm{~N}$, $19^{\circ} 05^{\prime} 07.27929^{\prime \prime} \mathrm{E}$. Altogether, 43 trees were located in the plot (534 trees/ha).

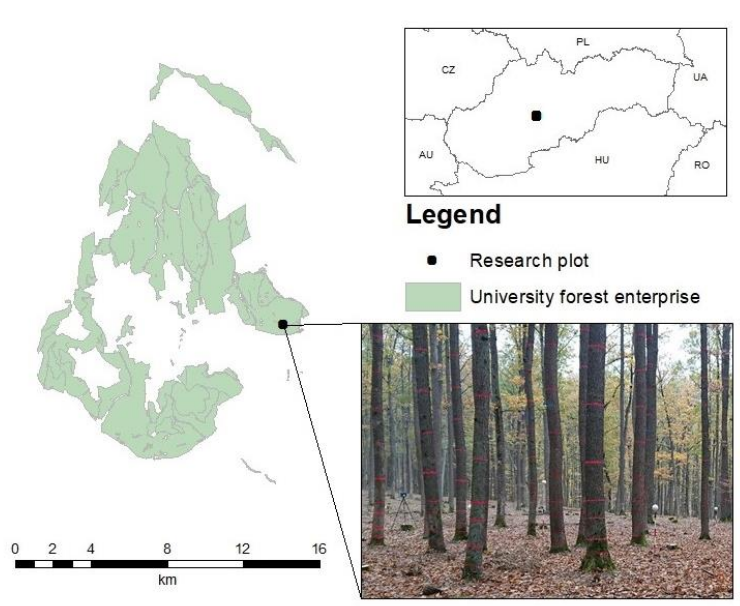

Figure 1.The study area - a managed forest located in the Central Slovakia

\subsection{Reference data}

The DBH were manually measured at height of $1.3 \mathrm{~m}$ using standard steel diameter tape. For each measurement, the $1.3 \mathrm{~m}$ height was determined individually by measuring tape. The positions of 43 trees were measured by the total station, and the angle offset method was used to determine the tree axes at the height of $1.3 \mathrm{~m}$ above the terrain. Except for tree position, the reference targets were placed on the plot and their polar coordinates were measured.

The reference data set was created in compliance with the legislation in force in the field of Forest mapping. In the Slovak Republic, two main laws have influence forest mapping (Slovak Technical Standards - STN; 1. Geodetic points and 2. Charts with scales 1:200, 1:250, 1:500, 1:1000. General and special charts). Essentially, the standards define the classes of accuracy valid for the geodetic control points, which are used as a base for calculation of the other consequential objects-representing points. The highest allowed coordinate and elevation errors are defined in the classes of accuracy (Table 1).

The fifth class of accuracy is used in the field of forestry which is brought about by GNSS decreasing effects of forest stands. However, the reference data set was collected with the aim to reach at least the third class of STN - Geodetic control points (the highest allowed error $0.06 \mathrm{~m}$; Table 1.). 


\begin{tabular}{|c|c|c|c|}
\hline \multirow{2}{*}{$\begin{array}{c}\text { The class } \\
\text { of accuracy } \\
{[\mathrm{m}]}\end{array}$} & \multirow{2}{*}{$\begin{array}{l}\text { Geodetic } \\
\text { points } \\
\text { Geodetic } \\
\text { control } \\
\text { points }\end{array}$} & \multicolumn{2}{|c|}{$\begin{array}{l}\text { Charts with scales: } \\
\text { 1:200, 1:250, 1:500, 1:1000. } \\
\text { General and special charts. }\end{array}$} \\
\hline & & $\begin{array}{l}\text { Positional } \\
\text { points }\end{array}$ & Elevation points \\
\hline 1 & 0.02 & 0.04 & 0.03 \\
\hline 2 & 0.04 & 0.08 & 0.07 \\
\hline 3 & 0.06 & 0.14 & 0.12 \\
\hline 4 & - & 0.26 & 0.18 \\
\hline 5 & - & 0.50 & 0.35 \\
\hline
\end{tabular}

Table 1. The classes of accuracy according to the Slovak Technical Standards

The collected reference data encompassed position and DBH of 43 trees and the coordinates of reference targets, which were localized in the plot. The position and DBH of trees were collected between ZEB REVO (the data collection in autumn of 2018) and ZEB HORIZON (the data collection in spring of 2019) data collection, and position of reference targets were collected right after the plot was record with both one of the scanners. To collect coordinates of trees permanent points, three orientation points, and two standpoints for the total station were needed to be built up. The points were permanently stabilized, signalled and measured using GNSS receiver Topcon Hiper SR. The coordinates were calculated from 15 minutes records of satellite observation logged by the receiver on each permanent point. The post-processing method of calculation coordinates was used.

The tree position was measured using the total station Topcon 9000 , via the principle of the spatial polar method. The spatial position of measured points was calculated from the measured horizontal and vertical angles and the measured slope distance (Erdélyi, 2015). The position of tree axes at the height of $1.3 \mathrm{~m}$ was measured with the horizontal angle offset application when the target height from the first observation is applied to the horizontal angle offset observation (Trimble Inc., 2018). Finally, the tree defining polar coordinates were transferred to Cartesian coordinates.

Unfortunately, the reference targets, which were used early in autumn of 2018, were destroyed. Therefore, other reference targets had to be created in the spring of 2019. The breast height was marked on every tree in the plot ahead of the experiment. The reference targets were located on the signs on the trees at the height of $1.3 \mathrm{~m}$ (the breast height) in order to transform the point cloud to a commonly used coordinate system. The four targets were placed on each of six trees, on the perimeter of a trunk in two perpendicular directions. The trees on the edge and in the middle of the plot were picked for this purpose. The nine targets were placed on trees near the ZEB HORIZON planed trajectory. The polar coordinates of reference targets were measured after HMLS data collection. The same equipment, technology, the three orientation points, and two total station's standpoints were used as in the case of the previous targets collection. The 33 new reference targets were measured and 24 were used to transform the ZEB HORIZON point cloud from local to the commonly used coordinate system.

\subsection{Experimental data}

The data were collected by two types of devices, developed by GeoSLAM Ltd. (UK), ZEB REVO and ZEB HORIZON as lightweight handheld mobile scanners, Figure 2 . Both devices are composed of a laser scanner, a low-cost Inertial Measurement Unite (IMU), a camera, a data logger and accessories (Chen et al., 2019; Ryding et al., 2015).

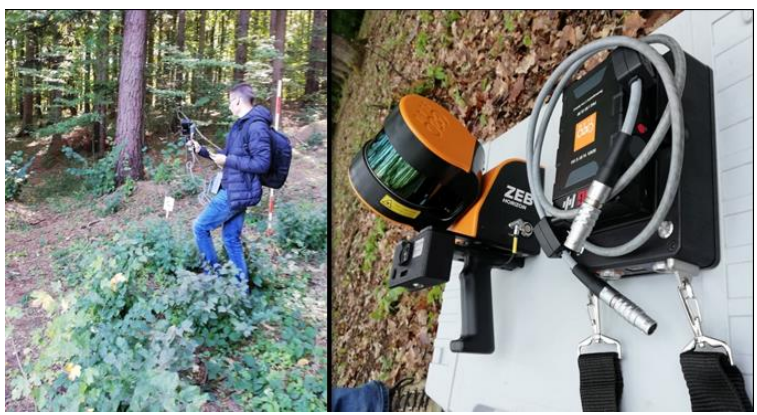

Figure 2. Left side - ZEB REVO in data acquisition process; Right side - ZEB HORIZON

A laser scanner ZEB REVO provides 43,200 measurements per second with a maximum range of $30 \mathrm{~m}$ and relative positional accuracy of $2-3 \mathrm{~cm}$ depending on the environment conditions. The second used device, the ZEB HORIZON, provides 300,000 points per second with a maximal range of $100 \mathrm{~m}$ and accuracy of $1-3 \mathrm{~cm}$. The laser wavelength of both devices is comparable. Both devices contain eye-safe laser. Detailed technical specifications of ZEB REVO and ZEB HORIZON are show in Table 2.

\begin{tabular}{ccc}
\hline PARAMETER & ZEB REVO & ZEB HORIZON \\
\hline Scanner & $\begin{array}{c}\text { Hokuyo UTM- } \\
30 \mathrm{LX}-\mathrm{F}\end{array}$ & $\begin{array}{c}\text { Velodyne Puck } \\
\text { VLP-16 }\end{array}$ \\
\hline Maximum Range & $30 \mathrm{~m}^{*}$ & $100 \mathrm{~m}$ \\
\hline $\begin{array}{c}\text { Data Acquisition } \\
\text { Rate }\end{array}$ & $\begin{array}{c}43200 \\
\text { points/sec }\end{array}$ & $\begin{array}{c}300000 \\
\text { points } / \mathrm{sec}\end{array}$ \\
\hline $\begin{array}{c}\text { Relative Position } \\
\text { Accuracy }\end{array}$ & $2-3 \mathrm{~cm} * *$ & $1-3 \mathrm{~cm}$ \\
\hline $\begin{array}{c}\text { Absolute Position } \\
\text { Accuracy }\end{array}$ & $3-30 \mathrm{~cm}$ & - \\
\hline $\begin{array}{c}\text { Horizontal } \\
\text { Resolution }\end{array}$ & $0.625^{\circ}$ & $0.1-0.4^{\circ}$ \\
\hline $\begin{array}{c}\text { Vertical } \\
\text { Resolution }\end{array}$ & $1.8^{\circ}$ & $2^{\circ}$ \\
\hline FOV & $270^{\circ} \times 360^{\circ}$ & $130^{\circ}$ \\
\hline Rotation Speed & $0.5 \mathrm{~Hz}$ & $10 \mathrm{~Hz}$ \\
\hline Battery life & $\begin{array}{c}4 \mathrm{hours} \\
\text { continuous use }\end{array}$ & $3.5 \mathrm{hours}$ \\
\hline $\begin{array}{c}\text { Weight (total } \\
\text { system) }\end{array}$ & $4.1 \mathrm{~kg}$ & $2.4 \mathrm{~kg}$ \\
\hline Backpack & $\begin{array}{c}180 \mathrm{x} 220 \mathrm{x} \\
470 \mathrm{~mm}\end{array}$ & $\begin{array}{c}\text { Backpack or } \\
\text { shoulder strap }\end{array}$ \\
\hline Markm
\end{tabular}

* Maximum range to Kodak white card indoors (90\% reflectivity) Outdoors range may be reduced to $15-20 \mathrm{~m}$ depending on environmental conditions

** A number of environmental factors can influence trajectory accuracy

Table 2. Technical specifications of ZEB REVO and ZEB HORIZON 
The recording of the plot took approximately 10 min.. After 15 20 seconds of initialization record the acquisition was executed. Both devices used for the data collection work on the principles of SLAM. The data is recorded when the head of the scanner moves vertically and the device operator moves across the plot. The operator's movement with the device provides the third dimension. SLAM processing to generate accurate 3D point clouds from data was performed with the GeoSLAM Hub software.

\subsection{ZEB REVO data collection and processing}

The data were acquired with the aim of the highest objects surface coverage. To record the data, the free walking method was used and the plot was circumvented along the outer edge of the circular plot with a radius of $16 \mathrm{~m}$. The closed-loop was used for the survey i.e. the recording starts and ends at the same point. The survey was conducted in October 2018. To assess the accuracy of the location, the transformation to the commonly used coordinate system was needed. The six reference targets were used to transform the point cloud from local to the commonly used coordinate system. As a consequence of RGB information absence in the point cloud, the full automated target identification was not possible. The identification of targets was made another way, instead. Since the identification of the relatively small object in the point cloud was difficult, it was split into 64 point clouds, created based on the user-defined grid. After identification of the point clouds which contain reference target, the calculation of the target central point was needed. The $0.5 \mathrm{~m}$ wide circular shapefile was placed around the target position and this area was split again to the small partial point cloud containing only target and its close surroundings. The next step was needed because of the dispersion of point cloud, brought about by the data inconsistency. Apart from positional information, the point cloud contains GNSS time data. Based on this the partial point clouds were assorted by the histogram of GNSS time (Čerňava et al., 2019). The histogram bin width was $0.5 ; 0.25$ and $0.01 \mathrm{~s}$, chosen individually by the density and the dispersion. Several point clouds were extracted and were able to choose point clouds with the best projection for each of the six targets. Subsequently, the manual filtration was made, terrain, a stick of target, and incorrect points were removed, Figure 3.

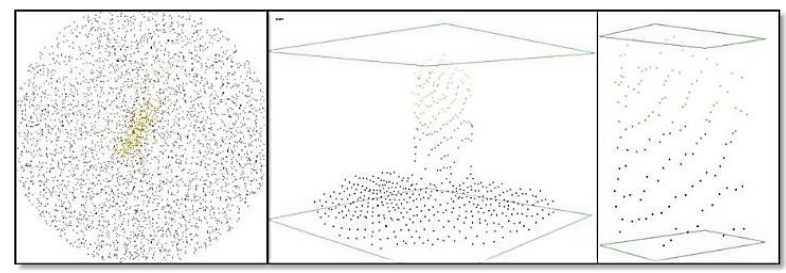

Figure 3. Illustration of the point cloud modification for the derivation of the target's centre position.

\subsection{ZEB HORIZON data collection and processing}

The survey was conducted in May 2019. A specific scan path shown in Figure 4 was used to obtain consistent data. Around the circular plot, a $60 \mathrm{~m} \times 60 \mathrm{~m}$ square subplot was created. Around the perimeter of the subplot at regular intervals, the reference spheres and the wooden reference sticks were placed, for better orientation in the process of data acquisition. Before the data acquisition, the initialization of IMU was needed. The trajectory was between orientation points (spheres and sticks). During the data acquisition the movement of the device in the direction of the orthogonal triad axes was reduced. The closedloop for the survey and the same point for the start and end of the recording were used again.

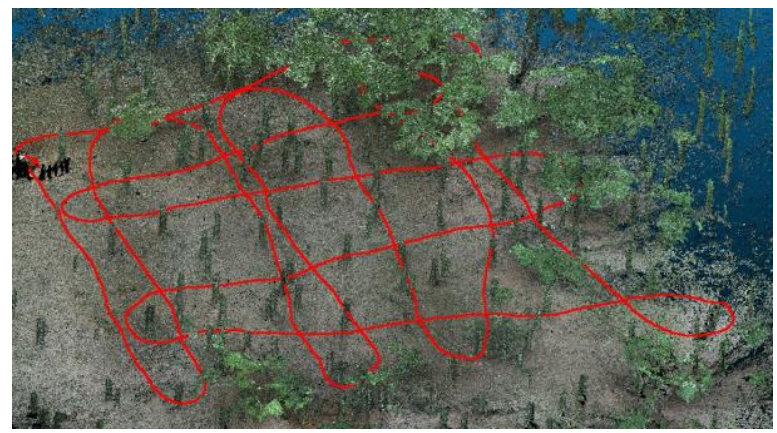

Figure 4. The specific scan path of ZEB HORIZON during the data acquisition

From 33 new measured reference targets 24 (on the 6 trees) were used to transform the point cloud from local to the commonly used coordinate system. The position of trees axes, calculated from reference targets for every single tree, as the point of intersection of two line segments, connecting the central points of targets located on the trunks (Figure 5) were calculated in the surveyor program Kokeš 14.13 and prepared for the transformation of the point cloud. This group of 6 trees was not included in positional accuracy evaluation.

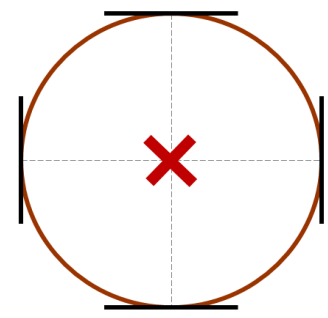

Figure 5. The schematic representation of the position of targets on the perimeter of a trunk

\subsection{The transformation of point clouds}

The transformation of point clouds was made with point pair picking tool in CloudCompare 2.10.2 Zephyrus, by identification of the couples of coordinates (the local coordinates calculated from point cloud matched with the real coordinates). Based on the coupled coordinates, the rigid transformation matrices, as a composition of a rotation and a translation, were calculated to apply these matrices on the booth HMLS point clouds. This way the transformation from the local coordinate system to the coordinate system of Datum of Uniform Trigonometric Cadastral Network (S-JTSK) was made.

\subsection{Estimation of tree position}

The estimation of tree position was connected with the estimation of tree diameter. For this purpose, the DendroCloud software was used (Koreň et al., 2017). The calculation started with creating the digital terrain model with the vertical projection module. A two-dimensional output grid was filled up with a vertical projection of any attribute of a point cloud. At a height of $1.25-1.35 \mathrm{~m}$ above the surface a cross-section was made and the points from this interval were extracted. An important step of the process was spatial clustering when the 
points were assigned to cluster with a user-defined maximal distance of points and a minimal number of points in one cluster. The cross-section analysis was made based on spatial clusters of point cloud cross-section, and the estimation of tree position and DBH were calculated in this step by circle fitting methods. These features were calculated by refining methods of diameter estimation, which improve initial methods (the minimum bounding box method, the centroid method, and maximum distance method) by using optimization algorithms with the purpose of minimizing the root mean square error (RMSE) of circle-fitting residuals. From this group, the Monte Carlo method was used. Its improvement consists of regulating the circle's position and diameter by generating a large number of small shifts in the diameter and position of the circle. It selects the circle with the smallest RMSE, thereafter. The output was export as an ASCII text file. Detailed information about the workflow used within the software can be found in Koren (2019). The reference tree positions were identified with subsequent estimation.

\subsection{Study methods}

The evaluation of the tree position started using the following equation to calculate the positional differences $e_{i}$, where $x_{\text {ref }}$ is the reference coordinate and $\mathrm{x}_{\mathrm{est}}$ is estimated coordinate, in the direction of the $\mathrm{x}$-axis, $\mathrm{y}$-axis, and $\mathrm{z}$-axis. Indicating the deviation of the values the Bias is the measure of the systematic component of error. RMSE of positions and estimated tree diameters is an indicator of the precision and accuracy of data. The distance in 3D space as a straight line between two points: reference and derived positions, was calculated. This step provided the ability to test positional accuracy with the mean square error (MSE). Interpretation of the described characteristics deals with the measure of precision and accuracy of the data. The following equations were used for the evaluation of the tree position.

$$
\begin{aligned}
& \theta_{i[x)}=x_{r e f}-x_{\text {est }} \\
& \text { bias }=\frac{\sum e_{n \mathrm{n}}}{n}
\end{aligned}
$$

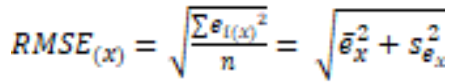

$$
\begin{aligned}
& \text { MSE }=\frac{\sum e_{x}^{2}}{n}+\frac{\sum e_{p}^{m}}{n}+\frac{\sum e_{n}^{2}}{n} \\
& \text { RMSE }=\sqrt{\text { MSE }}=\sqrt{\frac{\sum e_{n}^{2}}{n}+\frac{\sum e_{p}^{2}}{n}+\frac{\sum e_{i}^{2}}{n}}
\end{aligned}
$$

Where: $\mathrm{x}, \mathrm{y}, \mathrm{z}=$ object coordinates

$\mathrm{n}=$ number of identified trees

$\mathrm{s}_{\mathrm{e}}=$ standard deviation

The equations 1-5 were adjusted for DBH estimation accuracy evaluation with substitution of $\mathrm{x}_{\mathrm{ref}}, \mathrm{y}_{\mathrm{ref}}, \mathrm{z}_{\mathrm{ref}}$ and $\mathrm{x}_{\mathrm{est}}, \mathrm{y}_{\mathrm{est}}, \mathrm{z}_{\mathrm{est}}$ by $\mathrm{DBH}_{\text {est }}$ and $\mathrm{DBH}_{\text {ref. }}$.

\section{RESULTS}

In this study, we attempt to use high precision data in order to achieve an objective evaluation of experimental data, collected by HMLS devices with SLAM technology, on account of the assumption that it eliminates one of the most decreasing factors, which forest environment is the cause of. The maximal accepted error of reference data was $4 \mathrm{~cm}$.

\subsection{Data collection}

Using the ZEB REVO data set 38 trees were modelled in sufficient quality; this number of trees was used to calculate the positional differences and DBH estimation. Using the ZEB HORIZON all 43 trees were modelled in sufficient quality. Due to device's range $(100 \mathrm{~m})$ the study area wide surrounding was recorded and many trees outside the research plot were modelled, these were excluded from the final evaluation. Because of faster data processing, the study area and near surrounding were clipped from ZEB HORIZON primal point cloud.

Although the data collecting time of both devices was comparable, the trajectories were different. The distinct difference is in the number of points on the trajectory in relation to the approximate length of the trajectories Table 3 . This is the consequence of the data collection oriented on density of point cloud during the ZEB REVO data collection. The disadvantage of this workflow based on visual assessment is various density of point cloud causing the inconsistency of data.

\begin{tabular}{ccc}
\hline Parameter & ZEB REVO & ZEB HORIZON \\
\hline $\begin{array}{c}\text { Trajectory (number } \\
\text { of points) }\end{array}$ & 57,824 & 40,765 \\
\hline $\begin{array}{c}\text { Length } \\
\text { (approximately) }\end{array}$ & $240 \mathrm{~m}$ & $610 \mathrm{~m}$ \\
\hline
\end{tabular}

Table 3. Approximate length and number of trajectory points

\subsection{Data processing}

The RMSE of derived positions from point cloud produced by SLAM devices were as follows (Table 4). The REVO's positional RMSE is $25.3 \mathrm{~cm}$ (derived from MS $\mathrm{E}$ for: $\mathrm{x}$ axis $=$ $2.02 \mathrm{~cm}$; $\mathrm{y}$ axis $=2.98 \mathrm{~cm}$; $\mathrm{z}$ axis $=1.39 \mathrm{~cm}$ ). The HORIZON's positional RMSE is $28.4 \mathrm{~cm}$ (derived from Mean Square Error for: $\mathrm{x}$ axis $=2.34 \mathrm{~cm}$; $\mathrm{y}$ axis $=5.49 \mathrm{~cm} ; \mathrm{z}$ axis $=2.11 \mathrm{~cm}$ ).

\begin{tabular}{lcccc}
\hline \multicolumn{5}{c}{ ZEB REVO } \\
\hline MSE & $\mathrm{x}$ & $\mathrm{y}$ & $\mathrm{z}$ & OVERALL \\
\hline RMSE [m] & 0.020 & 0.030 & 0.014 & 0.064 \\
\hline \multicolumn{5}{c}{ ZEB HORIZON } \\
\hline MSE & $\mathrm{x}$ & $\mathrm{y}$ & $\mathrm{z}$ & OVERALL \\
\hline RMSE [m] & 0.023 & 0.055 & 0.002 & 0.081 \\
\hline Table 4. Comparison of the errors of estimated positions
\end{tabular}

The RMSE of estimated tree diameters by REVO and HORIZON device was $3.28 \mathrm{~cm}(\mathrm{rRMSE}=10.66 \%)$ and 1.65 $\mathrm{cm}(\mathrm{rRMSE}=5.20 \%)$ respectively.

\begin{tabular}{ccc}
\hline \multicolumn{3}{c}{ ZEB REVO } \\
\hline Bias [cm] & RMSE [cm] & rRMSE [\%] \\
\hline-1.75 & 3.28 & 10.66 \\
\hline \multicolumn{3}{c}{ ZEB HORIZON } \\
\hline Bias [cm] & RMSE [cm] & rRMSE [\%]
\end{tabular}


$-1.54$

1.65

5.20

Table 5. Comparison of the errors of estimated DBH

ZEB REVO had two times worse accuracy of DBH estimation as ZEB HORIZON. This was due to the higher amount of points on the trunks. On the other hand, the positional accuracy of trees was slightly higher in the case of ZEB REVO. The measured reference data reached the highest precision level according to the Slovak accuracy standards for land surveys. Therefore, the positional RMSE of both devices was within the limits of the standards for forest mapping. SLAM devices calculate their position by scanning the surrounding objects and by considering the changes of the objects' position relative to the change in the device's position. We assume that the shapesimilar objects located on the edge of the device reach can adversely affect the accuracy. It is crucial to study the impact of this phenomenon to improve the positional accuracy.

\section{DISCUSSION}

We tested two hand-held laser scanners within a forest environment for accurate position and DBH estimation. These devices (ZEB HORIZON and ZEB REVO) differ mainly in the range and acquisition rate. These parameters caused significant difference in DBH estimation, where the ZEB HORIZON with higher range and rate had the RSME of DBH about a half the size as the ZEB REVO. In overall the tree position was not significantly different. We can clearly state that those devices with used data acquisition and processing workflow are suitable for multipurpose use in the forest environment.

In Ryding et al. (2015), where the concept of the ability to successfully extract DBH and stem position from SLAM device ZEB 1 outputs was demonstrated and compared against TLS survey, the extracted DBH and stem position information had RMSE of $1.5 \mathrm{~cm}$ and $2.1 \mathrm{~cm}$, respectively, and it is considered an excellent result. The HMLS data were compared against TLS data sets and the stems with a DBH $>10 \mathrm{~cm}$ were examined. However, TLS data were not compared with high accuracy reference data. In this study, the effort to collect reference data with higher accuracy as the lowest accepted error which complied with Slovak accuracy standards for land surveyors (Table 1) was expended, and the data which were used in the transformation process and reference tree positions were measured with the highest allowed coordinate and elevation error at the centimetre level, the maximal accepted error was 4 $\mathrm{cm}$. Evaluation of 6 different MLS devices used in urban areas was done by Puente et al. (2013), positional accuracy of the devices in $\mathrm{x}$ and $\mathrm{y}$ axis ranged from $0.1 \mathrm{~m}$ up to $0.265 \mathrm{~m}, \mathrm{z}$ axis accuracy ranged from $0.07 \mathrm{~m}$ to $0.24 \mathrm{~m}$. The potential of SLAM smartphone devices for DBH and tree position estimation with real-time appearance-based mapping (RTAB-Map) as the backend and Trunk-based backend for large scale forest inventories was studied by Fan et al. (2020). RTAB-Map backend reached RMSE higher than $0.3 \mathrm{~m}$ in the $\mathrm{x}$-axis, $\mathrm{y}$-axis and $\mathrm{z}$-axis. With the Trunk-based backend, they were able to reach the best RMSE in one axis direction of $0.078 \mathrm{~m}$ what makes Trunk-based backend application slightly more accurate compared to our best single direction results $0.104 \mathrm{~m}$ with ZEB REVO and less accurate as ZEB HORIZON $0.046 \mathrm{~m}$. The method of accurate positional reference data of acquisition by the total station and comparing with tree positions derived from point cloud created by HMLS ZEB REVO RT with planned serpentine scanning path brought overall RMSE of tree position derivation $0.26 \mathrm{~m}$ (Chen et al., 2019), what is similar to result present in Table 4.
Standard forestry field survey (FS) data collection is time consuming and human resources demanding. Typically, survey is done by a group of professionals, while it does not reach a great level of detail in comparison with any of laser scanning methods. However, all scanning methods require additional processing time whilst field survey is normally completed on site (Ryding et al., 2015). The potential of forest environment data acquisition by MLS systems in forestry was studied by Černava et al. (2019). Despite the good accuracy and fast data collection, rough terrain with numerous obstacles might be the challenge for the use of MLS devices and dense forest road network will be necessary to create access. Survey times in our research plot were recorded and compared with studies focused on TLS, HMLS, and close-range photogrammetry (CRP) methods. CRP was included due to data acquisition speed and low money demands and human resources. However, the point cloud is generated during the post-processing and thus it can be more time consuming than using HMLS, because the speed of point cloud creating strongly depends on the available hardware. Table 6 shows differences in related studies and underlines the rate of data acquisition by HMLS. In addition, it shows even greater potential in larger-scale area surveys because the area scanned in one minute is increasing with the size of the examined area. However, the relation between the size of area and the time on site was not statistically tested. Therefore, optimal size of the area of interest needs to be examined in the future studies. In this submission we address the problem of positional accuracy under the forest canopy, therefore we would like to compare the aspect of time consumption using the method with the highest possible accuracy (total station and the principle of the spatial polar method) and HMLS. Considering the pre-processing time of GPS observations of 15 minutes on each of 5 stabilized positions and measurement of all tree positions we spent 195 minutes on site. The time needed for measurement of one point will be reduce rapidly with the number of measured points as it can be counted in seconds.

\begin{tabular}{|c|c|c|c|c|c|}
\hline \multirow[b]{2}{*}{ Author } & \multirow{2}{*}{$\begin{array}{l}\text { Total } \\
\text { area } \\
{\left[\mathrm{m}^{2}\right]}\end{array}$} & \multicolumn{4}{|c|}{ Method (m²/min per surveyor) } \\
\hline & & TLS & HMLS & FS & $\begin{array}{c}\text { CRP } \\
\text { (mobile) }\end{array}$ \\
\hline \multirow{3}{*}{$\begin{array}{l}\text { Ryding et al. } \\
(2015)\end{array}$} & 100 & 0.85 & 20 & - & - \\
\hline & 500 & - & 50 & - & - \\
\hline & 2,500 & - & - & $\begin{array}{c}0.4 \\
3\end{array}$ & - \\
\hline \multirow{2}{*}{$\begin{array}{l}\text { Cabo et al. } \\
\text { (2018) }\end{array}$} & $\begin{array}{c}1,000 \\
0\end{array}$ & $\begin{array}{c}51.5 \\
5\end{array}$ & 107.53 & - & - \\
\hline & 5,000 & $\begin{array}{c}72.4 \\
6 \\
\end{array}$ & 277.78 & - & - \\
\hline $\begin{array}{l}\text { Quinton and } \\
\text { James (2013) }\end{array}$ & 780 & 26 & 123.81 & - & - \\
\hline $\begin{array}{l}\text { Chen et al. } \\
\text { (2019) }\end{array}$ & 300 & - & 30 & $\begin{array}{c}0.9 \\
1 \\
\end{array}$ & - \\
\hline $\begin{array}{l}\text { Mokroš et al. } \\
2018\end{array}$ & 1225 & - & - & - & 136 \\
\hline Our results & $\begin{array}{c}804 \\
3,600\end{array}$ & $\begin{array}{c}8.29 \\
-\end{array}$ & $\begin{array}{l}80.4 \\
300 \\
\end{array}$ & $\begin{array}{c}1.04 \\
-\end{array}$ & - \\
\hline
\end{tabular}

Table 6. Comparison of efficiency of different approaches for data acquisition

HMLS directly acquires hundreds of thousands of points within minutes. Scanning time in our research plot took 10 minutes by ZEB REVO and 12 minutes by HORIZON; time difference is caused by different scanning path which was more than 2.5 times longer in second case (Table 3). The trajectory of ZEB 
HORIZON was planned as a serpentine scanning path. Because of the range $(100 \mathrm{~m})$ of the device (Table 2) the circular plot was recorded as a part of a $60 \mathrm{~m} \times 60 \mathrm{~m}$ square subplot, where the distance between trajectory lines was $10 \mathrm{~m}$. The research plot was clipped from the point cloud and processed with the same workflow as was used in the ZEB REVO case.

As on one of the most important variables for forestry, different authors focus on DBH estimation, with different approaches. For example Liang et al. (2016) created a great overview of TLS techniques related to forest inventories and reported that accuracy of DBH estimation varied from $0.7 \mathrm{~cm}$ to $7.0 \mathrm{~cm}(1.8$ $-3.3 \mathrm{~cm}, 3.4-7.0 \mathrm{~cm}, 0.7-2.4 \mathrm{~cm}$, and $2.0-4.2 \mathrm{~cm})$, Čerňava et al. (2019) estimated DBH based on MLS system adjusted for forest environment which is shown to be the fastest data collection ground based approach with RMSE of DBH $3.06 \mathrm{~cm}$, more portable backpack method using SLAM achieved high accuracy in steam curve estimation (RMSE of the extracted stem curves was $1.2 \mathrm{~cm}$ and $1.7 \mathrm{~cm}$ ) comparing to TLS references (Hyyppä et al., 2020b), Under-canopy UAV laser scanning method with SLAM corrected point cloud collection was presented as accurate and efficient in comparison with multi-scan TLS approach (Hyyppä et al., 2020a) where RMSE values for the DBH were $0.69 \mathrm{~cm}$ at the sparse plot, and 0.92 $\mathrm{cm}$ in the obstructed plot. We presents results compared against reference data collected in forest environment measured with the highest accuracy requirements. Table 5 shows the systematic underestimation of reference measurements in both HMLS devices ZEB HORIZON and ZEB REVO $(-1.54 \mathrm{~cm}$ and -1.75 $\mathrm{cm}$ ), which is from our previous experience a common problem of circle fitting algorithms. Other authors claim underestimated DBH e.g. Ryding et al. (2015) in subplot A1 with diameters 10 $\mathrm{cm}$ and higher presented bias $-1.2 \mathrm{~cm}$. Bauwens et al. (2016) calculated bias from $-0.08 \mathrm{~cm}$ (HMLS) up to $-1.17 \mathrm{~cm}$ (TLS). The results of DBH estimation by TLS methods summarized in Liang et al. (2016) in 3 of 4 cases involved underestimation, similarly Koreň et al. (2017) evaluated 5 methods for single scan and 5 methods for multi-scan TLS data with underestimated results in 9 cases. CRP as mentioned in Table 6 as one of the fast forest environment data collection method also showed negative bias values ranging from $-0.46 \mathrm{~cm}$ to $-2.63 \mathrm{~cm}$ (Mokroš et al., 2018).

We support opinion that one of the main advantages of HMLS is the small amount of fieldwork comparing to TLS, which requires few static positions of scanner supplemented by several reference spheres placed within the area of interest (Cabo et al., 2018; James and Quinton, 2014). However, we must highlight that from two devices used in this study we achieved better results with ZEB HORIZON with RMSE of $1.65 \mathrm{~cm}$ and rRMSE of $5.2 \%$, which is comparable with DBH estimation errors of TLS devices. RMSE of DBH estimation in 25 different research plots varied between 0.7 and $7.0 \mathrm{~cm}$ in Liang et al. (2016). We assume that lower accuracy of ZEB REVO (RMSE of $3.28 \mathrm{~cm}$ and rRMSE $10.66 \%$ ) is caused by the parameters of the scanner but also by the scanning trajectory, which might create noise points on the surface of the trunks, the inconsistency of scanned data and therefore, affect the process of diameter estimation. Hyyppä et al. (2020a) obtained better RMSE of DBH estimation $0.6 \mathrm{~cm}$ and rRMSE $2.2 \%$; however, estimations based on TLS point cloud were used as reference. MLS system with all the benefits of fast data collection over large areas were able to estimate DBH with RMSE $(3.06 \mathrm{~cm})$ (Čerňava et al., 2019) comparable to results of less accurate device ZEB REVO in our case. Low cost and fast CRP method show worse RMSE $(4.41 \mathrm{~cm}-5.98 \mathrm{~cm})$ and rRMSE $(16.67 \%$ -
$20.93 \%$ ) (Mokroš et al., 2018) than our results of HMLS. However, due to procurement costs of hardware needed, it might have great potential in forestry practise, especially for small forest land owners.

\section{CONCLUSION}

Some authors have demonstrated the potential of the HMLS technology so far (Bauwens et al., 2016; Cadena et al., 2016; James and Quinton, 2014; Ryding et al., 2015). This study contributes to the current state-of-art by using the highest possible accuracy reference data which we were able to collect in a forest environment in combination with powerful technology, and to describe the possibilities which provide this combination in the field of accurate positioning under the forest canopy. Beside the forestry practice the accurate localization in specific environment is very important for many other spheres. This study supports the opinion that HMLS and simultaneous localization and mapping are in the field of forestry very economic and useful technological solution for data capture, processing and evaluation of stand and individual tree characteristics for forest inventory, digital terrain model creating, parameterization of forest growth models, raw material extraction, harvesting volume computation, soil improvement, etc. The accurate positioning of object and phenomena as a unique species or wildfires situated in forest stands is important for the whole society. Therefore, prior to every measurement, we must consider whether the millimetre positional accuracy of the total station is necessary in the forest environment or the less accurate but detailed point cloud which still complies with the accuracy standards for land surveys is preferred.

\section{ACKNOWLEDGEMENTS}

This work is supported by the Internal Project Agency of Technical University in Zvolen (Grant No.12/2019) and by the Scientific Grant Agency of the Ministry of Education, Science, Research and Sport of the Slovak Republic under the grant VEGA 1/0335/20.

Thanks to the equipment support provided by 3 GON Slovakia s.r.o.

\section{REFERENCES}

Bauwens, S., Bartholomeus, H., Calders, K., Lejeune, P., 2016. Forest inventory with terrestrial LiDAR: A comparison of static and hand-held mobile laser scanning. Forests 7. https://doi.org/10.3390/f7060127

Cabo, C., Del Pozo, S., Rodríguez-Gonzálvez, P., Ordóñez, C., González-Aguilera, D., 2018. Comparing terrestrial laser scanning (TLS) and wearable laser scanning (WLS) for individual tree modeling at plot level. Remote Sens. 10. https://doi.org/10.3390/rs10040540

Cadena, C., Carlone, L., Carrillo, H., Latif, Y., Scaramuzza, D., Neira, J., Reid, I., Leonard, J.J., 2016. Past, present, and future of simultaneous localization and mapping: Toward the robust-perception age. IEEE Trans. Robot. 32, 13091332. https://doi.org/10.1109/TRO.2016.2624754

Čerňava, J., Mokroš, M., Tuček, J., Antal, M., Slatkovská, Z., 2019. Processing Chain for Estimation of Tree Diameter from GNSS-IMU-Based Mobile Laser Scanning Data. $\begin{array}{llll}\text { Remote } & \text { Sens. } & 11,\end{array}$ https://doi.org/10.3390/rs11060615

Chen, S., Liu, H., Feng, Z., Shen, C., Chen, P., 2019. 
Applicability of personal laser scanning in forestry inventory. PLoS One 14, 1-22. https://doi.org/10.1371/journal.pone.0211392

Erdélyi, J., 2015. Automated point clouds processing for deformation monitoring. Geoinformatics FCE CTU 14, 47-54. https://doi.org/10.14311/gi.14.2.5

Fan, Y., Feng, Z., Shen, C., Khan, T.U., Mannan, A., Gao, X., Chen, P., Saeed, S., 2020. A trunk-based SLAM backend for smartphones with online SLAM in large-scale forest inventories. ISPRS J. Photogramm. Remote Sens. 162, 41-49. https://doi.org/10.1016/j.isprsjprs.2020.02.006

Hyyppä, E., Hyyppä, J., Hakala, T., Kukko, A., Wulder, M.A., White, J.C., Pyörälä, J., Yu, X., Wang, Y., Virtanen, J.P., Pohjavirta, O., Liang, X., Holopainen, M., Kaartinen, H., 2020a. Under-canopy UAV laser scanning for accurate forest field measurements. ISPRS J. Photogramm. Remote Sens. 164, 41-60. https://doi.org/10.1016/j.isprsjprs.2020.03.021

Hyyppä, E., Kukko, A., Kaijaluoto, R., White, J.C., Wulder, M.A., Pyörälä, J., Liang, X., Yu, X., Wang, Y., Kaartinen, H., Virtanen, J.P., Hyyppä, J., 2020 b. Accurate derivation of stem curve and volume using backpack mobile laser scanning. ISPRS J. Photogramm. Remote Sens. 161, 246-262. https://doi.org/10.1016/j.isprsjprs.2020.01.018

Hyyppä, J., Virtanen, J.P., Jaakkola, A., Yu, X., Hyyppä, H., Liang, X., 2017. Feasibility of Google Tango and kinect for crowdsourcing forestry information. Forests 9, 1-14. https://doi.org/10.3390/f9010006

James, M.R., Quinton, J.N., 2014. Ultra-rapid topographic surveying for complex environments: The hand-held mobile laser scanner (HMLS). Earth Surf. Process. Landforms 39 ,

$138-142$. https://doi.org/10.1002/esp.3489

Koreň, M., 2019. DendroCloud User Guide: Version1.49.

Koreň, M., Mokroš, M., Bucha, T., 2017. Accuracy of tree diameter estimation from terrestrial laser scanning by circle-fitting methods. Int. J. Appl. Earth Obs. Geoinf. 63, 122-128. https://doi.org/10.1016/j.jag.2017.07.015

Liang, X., Hyyppä, J., Kaartinen, H., Lehtomäki, M., Pyörälä, J., Yu, X., Pfeifer, N., Brolly, G., Francesco, P., Hackenberg, J., Huang, H., Jo, H.W., Katoh, M., Liu, L., Mokroš, M., Morel, J., Olofsson, K., Poveda-Lopez, J., Trochta, J., Wang, D., Wang, J., Xi, Z., Yang, B., Zheng, G., Kankare, V., Vastaranta, M., Wang, Y., 2019. International benchmarking of terrestrial laser scanning approaches for forest inventories. Off. Publ. - EuroSDR 2019 ,

$1-53$. https://doi.org/10.1016/j.isprsjprs.2016.01.006

Liang, X., Kankare, V., Hyyppä, J., Wang, Y., Kukko, A., Haggrén, H., Yu, X., Kaartinen, H., Jaakkola, A., Guan, F., Holopainen, M., Vastaranta, M., 2016. Terrestrial laser scanning in forest inventories. ISPRS J. Photogramm. Remote Sens. 115, 63-77. https://doi.org/10.1016/J.ISPRSJPRS.2016.01.006

Mokroš, M., Liang, X., Surový, P., Valent, P., Čerňava, J., Chudý, F., Tunák, D., Saloň, I., Merganič, J., 2018. Evaluation of close-Range photogrammetry image collection methods for estimating tree diameters. ISPRS Int. J. Geo-Information 7 . https://doi.org/10.3390/ijgi7030093

Oveland, I., Hauglin, M., Giannetti, F., Kjørsvik, N.S., Gobakken, T., 2018. Comparing three different ground based laser scanning methods for tree stem detection. Remote Sens. 10, 1-17. https://doi.org/10.3390/rs10040538
Oveland, I., Hauglin, M., Gobakken, T., Næsset, E., MaalenJohansen, I., 2017. Automatic estimation of tree position and stem diameter using a moving terrestrial laser scanner. Remote Sens. 9, 1-15. https://doi.org/10.3390/rs9040350

Perugia, B. Del, Giannetti, F., Chirici, G., Travaglini, D., 2019. Influence of scan density on the estimation of single-tree attributes by hand-held mobile laser scanning. Forests 10 , 1-13. https://doi.org/10.3390/f10030277

Puente, I., González-Jorge, H., Martínez-Sánchez, J., Arias, P., 2013. Review of mobile mapping and surveying technologies. Measurement 46, 2127-2145.

Ryding, J., Williams, E., Smith, M.J., Eichhorn, M.P., 2015. Assessing handheld mobile laser scanners for forest surveys. Remote Sens. 7, 1095-1111. https://doi.org/10.3390/rs70101095

Tomaštík, J., Saloň, Š., Tunák, D., Chudý, F., Kardoš, M., 2017. Tango in forests - An initial experience of the use of the new Google technology in connection with forest inventory tasks. Comput. Electron. Agric. 141, 109-117. https://doi.org/10.1016/j.compag.2017.07.015

Trimble Inc., 2018. No Title [WWW Document]. URL https://help.trimblegeospatial.com/TrimbleAccess/2018.0 0/en/HAngle_Offset.htm?TocPath=Measure\%7CConvent ional survey measure methods\%7CTo measure a topo point $\% 7 \mathrm{C}$

Tucek, J., Kardos, M., Tomastik, J., 2016. FIRST EXPERIENCE WITH PEDESTRIAN INERTIAL NAVIGATION SYSTEM APPLICATION UNDER FOREST CONDITIONS. REPORTS For. Res. Lesn. Vyzk. 61, 203-212.

Xie, P., Petovello, M.G., 2015. Measuring GNSS multipath distributions in urban canyon environments. IEEE Trans. Instrum. Meas. 64, 366-377. https://doi.org/10.1109/TIM.2014.2342452 